\title{
Multimodal Training as the Strategy of Human Resources Development in Conditions for Digital Transformation
}

\author{
Margarita $V l$. Ereshchenko ${ }^{1 *}$, Elena $G$. Zubareva ${ }^{1}$, and Svetlana S. Zubareva ${ }^{1}$ \\ ${ }^{1}$ Don State Technical University, 344000, Rostov-on-Don, Russia
}

\begin{abstract}
The purpose of this study was to explore the opportunities and risks associated with the implementation of new educational formats, including project laboratories, hackathons, startup challenge, co-working, microlearning with regard to their social and axiological aspects into training of high-skilled professionals. The article includes the review of priority areas of the modern education meeting the trends of the digital economy and the description of its specific characteristics. The paper also dwells on the models of cluster education developed by the group of tutors, containing problem cases, draft solution to socio-humanistic tasks, prototypes of engineering projects, business cases, and innovative entrepreneurship technologies. The conducted analysis shows that the use of the opportunities provided by modern educational technologies allows designing am individual educational path, selecting principal subjects and optional courses. During studies at the project office the students develop the skills and competences making them competitive in the global market. The work allowed for the analysis of advantages and disadvantages of the innovative forms and technologies of education into the educational process, as well as for the forecast regarding the efficiency of its long-term implementation.
\end{abstract}

In conditions of the digital transformation of the Russian society, the issue of training the skilled professionals able to ensure intensive economic development of Russia and bring its performance indicators in compliance with the global trends of developed competitive countries is of particular relevance. The university is a social institution providing a continuous flow of human resources. At the moment the higher educational institutions play a role of the center for production and accumulation of knowledge. However, to bring the level of human resources training in line with the needs of the contemporary society the implementation innovative network educational technologies is required. The application of the experimental platforms in the educational space started from the active implementation of the project method that was developed in the first half of the $20^{\text {th }}$ century. Ideas of the modular approach to the structuring of training material content found their theoretic treatment and development starting from the 1960s in the works of foreign and Russian scientists (S. Ya. Batyshev, B. and M. Goldschmid, V. V. Karpov, G. Owens, J Russell, Yu. F. Timofeeva, M. A. Choshanov, P. A. Yunyavichens). The commitment to innovation is linked to the trend towards creation of better conditions for the students within the framework

\footnotetext{
* Corresponding author: mar.ereshchenko@yandex.ru
} 
of new educational standards. This trend is especially relevant due to the fact that a distinctive feature of the modern generation of students is their deep involvement into digital technologies [1]. The implementation of innovative approaches to the education of this new generation at various levels of education is aimed at the development of their abilities for self-organization and the analysis of the personal development path. At the same time it helps in the development of the abilities essential for personal self-fulfillment in the professional activity.

The development of highly qualified personnel is considered in the context of multimodal education with the methods of social research, as well as methods of statistic data processing and visual presentation of results as line graphs. The experimental study was conducted with the participation of the student of Don State Technical University (DSTU). The study sample was 300 people. The study objects were engineering undergraduates. The study subject was the assessment of professional competences acquired in the course of multimodal education of Russian students in the digital educational environment.

Training of the digital generation in the educational environment is carried out in accordance with the requirements of Federal State Education Standards of Higher Education within the framework of basic professional bachelor's and master's degree programs (BPDP), among which the practice-oriented applied bachelor's programs aimed at maximum integration of education and the labor market hold a special place. The main aim of the professional training of future specialists is the provision of the maximum level of correlation between the results of BPDP acquisition - competences - and the requirements of hightechnology exercises [2]. The modular approach allows creating conditions to ensure correlation between the purpose of training and the content through identification of independent training units - modules - a basic concept of the modular education. The module is characterized by the uniformity of components: conceptual, organizational, methodological and technological. Each module has its aim, educational material, appropriate organizational forms, methods and techniques of training, methodic recommendations, as well as the list of diagnostic and control materials. Following their performance in one of the educational units the students design their personal educational path, selecting principal subjects and optional courses.

The advantages of the modular approach are the following: achievement of a clear structure of the educational material content of the course; implementation of variability through technological and conceptual flexibility of the modular structure of the educational program; openness of the content syllabus and its adaptation to the modern conditions of the professional activity at enterprises; individualization of the learning process through formation of personal educational paths; organization of the independent work in accordance with the specified didactic purposes.

Among the most effective educational technologies applied for training of new generation personnel there are project laboratories, hackathons, startup challenge, co-working and microlearning. These forms of training help expand the teacher-student and student-student interaction, as well as elevate involvement, performance and quality of education [3]. During the students' immersion into the project environment it is necessary to identify the level of their abilities, professional skills and preferences. Before approbation of the educational module the students were preliminary tested in order to determine identification markers: information security, technical competence, digital consumption, and digital communication. 


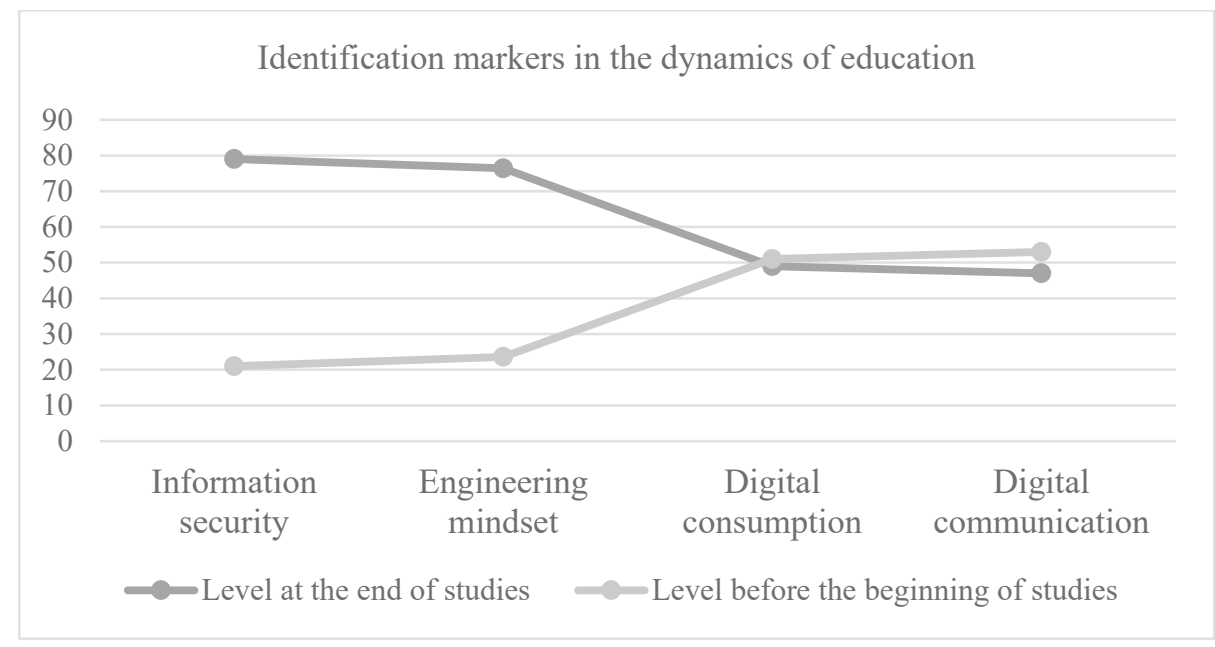

Fig. 1. Identification markers in the dynamics of education

According to the results of the empirical study presented in Figure 1, a significant increase is noted in the level of competence in such areas as information security and engineering mindset, while the level of digital consumption and communication remain unchanged.

In accordance with these indicators the students are divided into three clusters: "Think", "Invent" and "Solve".

"Solve" cluster contains draft solutions to socio-humanistic problems: future of engineering activities, labor migration, and development of the region. Implementation in the format of teamwork environment, where each person or a team is given an opportunity to share experience, to get free access to knowledge, professional communities, and competent experts, new ideas and technologies. Following the results of project work a solution to one of the selected subjects is developed.

"Invent" cluster involves designing and development of prototypes for engineering projects, problem cases from the plants-potential employers. Industrial co-working, mediapark and engineering school are suggested as an educational platform for implementation of this module.

"Think" cluster includes introduction into the project activity, basics of technological innovative entrepreneurship, theory of successful startup and educational projects within the selected field of studies. It involves work on a problem of practical importance in project offices of profession-oriented departments. Actual and relevant problem-based situations that modern plants face in their work are used as cases. The result of work is the presentation of solution to the problem case enclosed with the project data sheet.

Let us consider the implementation of a project office of "Think" cluster through the example of approbation at DSTU. The plan of work comprised 15 IT modules of project activity, including generation of personalized startup, demo-hackathon, brainstorming, and networking. The participants were tasked to solve one of theme-based engineering cases, dealing with the development of software products for the digital environment. During work in the module the tutor recorded not only the performance of participants when solving the production task, but also their skills, abilities, and the style of their work. We also intended to determine the readiness of students to work on projects and reveal difficulties they face in their work and their causes. 


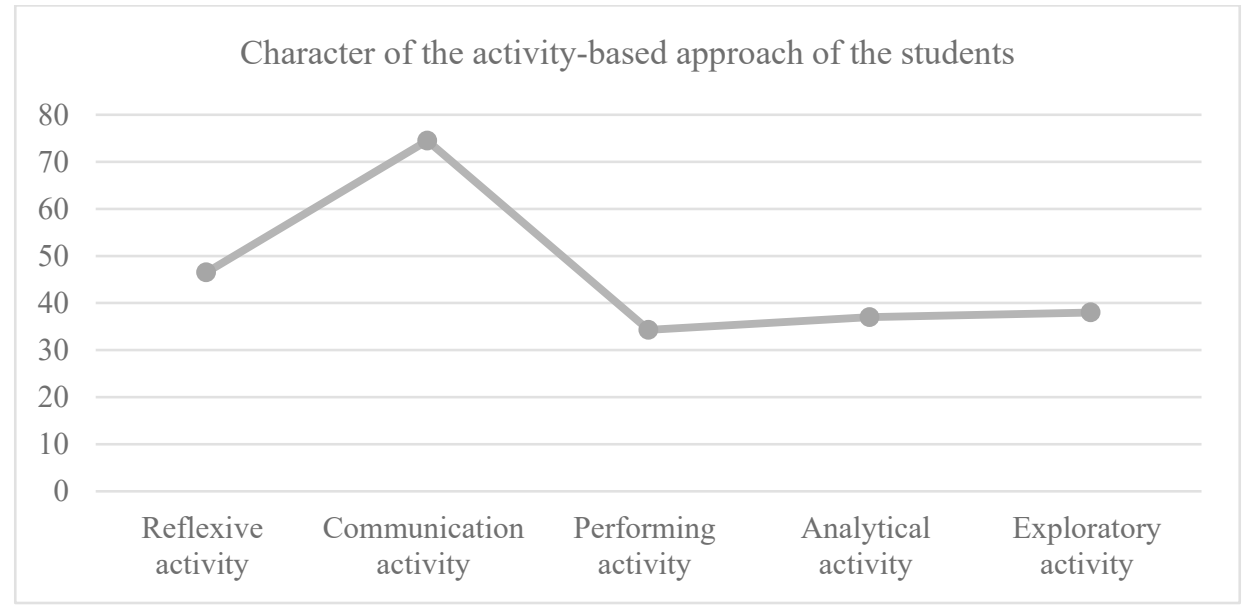

Fig. 2. Character of the activity-based approach of the students

Figure 2 shows the distribution of activity types when processing a project task. It is clear that performing activity related to the application of information technologies for solution of professional tasks in the majority of cases caused maximum difficulties. During project work students demonstrated skills of interaction with information services, including information, legal, analytical, business-planning, translation, and many others that they needed to achieve results on a real-time basis. Addressing to the social media in the course of studies is becoming one of the manifestations of the digital culture. In addition to educational gaming services these platforms involve communication and mutually-beneficial exchange of data and proposals between various subjects of the digital space [4]. A low level is also noted with regard to analytical and exploratory activities related to the processing of a large amount of information subject to analysis, including the data from normative legal documents regulating various types of work, which is determined by the lack of experience in conducting of scientific research in the study process. The most effective activity was the communication activity allowing for the assessment of competence level and personal professional qualities of the participants determining their joint activity.

In the course of study we also identified the style of study of the young generation, which is determined by generation peculiarities. For example, when working on solution of the case the students demonstrated the skills of quick search of necessary information; they applied the financial modeling method to make investment decisions; they expressed the desire to master skills of production business plan development and services provision in various economic sectors to maximize the income of their business; they tend to simplify the process of financial reporting preparation through application of analytical systems. However, during informal communication the signs of virtual isolation and alienation were noted. This is largely caused by social and psychological characteristics typical of the digital generation. It should be noted that one group of students demonstrated activation of their cognitive skills during immersion into non-conventional educational space, which allowed them to interact with maximum effectiveness in the suggested situation. At the same time, the other group had to find the most convenient and comfortable location in space as the major part of personal communication tool place in the virtual digital space.

The final assessment of the project work of students made during their studies in the program of multimodal education is made with a two-component model. Schematic representation of the assessment covers two areas that may be assigned with the score according to a number of criteria. 
Table 1. Criteria for project activity assessment

\begin{tabular}{|l|l|l|}
\hline Area & Criteria & Weight factor \\
\hline pontent & $\begin{array}{l}\text { Use of methods and tools } \\
\text { professing } \\
\text { Application of professional knowledge in this } \\
\text { subject area } \\
\text { Result suitability } \\
\text { Creativity } \\
\text { Overview of current trends } \\
\text { Economic review }\end{array}$ & \\
\hline $\begin{array}{l}\text { Problem-oriented } \\
\text { presentations }\end{array}$ & $\begin{array}{l}\text { Independence, personal initiative } \\
\text { Systematicity } \\
\text { Documentation } \\
\text { Literature review }\end{array}$ & \\
\hline
\end{tabular}

Thus, according to the data of Table 1, the assessment according to one of content processing criteria involves evaluation of practical skills and high-level competences. Criteria of problem-oriented presentation reflect corresponding competence. Similar assessment of the project activity is quite common for European educational institutions. At the same time it provides a full picture of the process of personnel training, design of professional education content and specific aspects of its content in conditions of integration between science, education and production, training of human resources with due account of psychological innovative R\&D activity.

During the studies in project laboratories the professional training quality was noted to improve. It is mainly determined by the introduction of intersectoral, trans-border, publicprivate models of interaction with potential employers and social partners. In these conditions the interests of future candidates and employers are united on the same educational platform. The concept of quality and prospects of personnel training based on the innovative mentalontological model of social partnership is designed [5]. Thus, the inclusion of supplementary modules into the education process in addition to classical form of education helps develop professional competences and essential skills, as well as develop personal qualities of the modern generation of students, and over a long term - training of the personnel able to introduce innovations in all areas of public life. However, the issue of axiological development of future generation in the context of transitive social space is still open.

Summarizing the above, we can draw the following conclusion. Establishment and development of the digital society and innovative economy make various social institutions face new unconventional tasks. In particular, the global system of education is undergoing transformations. Taking on the role of human resources production, it is under significant influence of digital economy that is challenged with needs for non-conventional solutions to production tasks. In view of this methods and techniques from other activity areas were integrated into the modern educational environment in order to develop professional competences meeting the requirements of innovative development. The groups of students formed according to their typical identification markers demonstrated expected abilities to solve the given tasks, and according to the study results they have substantially improved. During studies it is noted that the students' thinking abilities become more active, their style of work and communication manifest itself, and value orientations are revealed. Practiceoriented education in the context of multimodality is aimed to prepare students to solve tasks of digital economy. The maximum implementation of the personal potential substantially influences the self-actualization in the professional activity and the development of the modern society in general. 
1. M. Prensky, On the Horizon, IX, 21-22 (2001)

2. M. Stupina, Informatics and Education, 10, 19-22. (2017)

3. R. Chugh, U. Ruhi, Education and Information Technologies, 23 (2), 605-616 (2018)

4. M. Ereshchenko, E. Zubareva, S. Zubareva, INTED2019 Proceedings, 5895-5899 (2019)

5. T. Vlasova, E. Krasnova, V. Abraukhova, N. Safontseva, Journal of Social Studies Education Research, IX, 76-88 (2018) 